Int. J. Electrochem. Sci., 14 (2019) $7983-7994$

International Journal of

ELECTROCHEMICAL

SCIENCE

WWW.electrochemsci.org

\title{
Electrochemically Co-Deposition of Palladium Nanoparticles and Poly(1, 5-diaminonaphthalene) onto Multiwalled Carbon Nanotubes (MWCNTs) Modified Electrode and its Application for Amperometric Determination of Nitrite
}

\author{
Shukuan Shi ${ }^{1}$, Zhiting $\mathrm{Li}^{1}$, Yuxiao Chen ${ }^{2}$, Juan Yang ${ }^{2}$, He Xu ${ }^{1 *}$, Jinye Huang ${ }^{1}$, \\ Yuqi Zhang ${ }^{1}$, Chen Zoul, Jinli Qiao ${ }^{1, *}$ \\ ${ }^{1}$ State Environmental Protection Engineering Center for Pollution Treatment and Control in Textile \\ Industry, College of Environmental Science and Engineering, Donghua University, 2999 Ren'min \\ North Road, Songjiang District, Shanghai 201620, P. R. China \\ ${ }^{2}$ Technical Center for Industrial Product and Raw Material Inspection Testing of Shanghai Entry-Exit \\ Inspection and Quarantine Bureau, 1208 Min’ sheng Road, Pudong District, Shanghai, 200002, P. R. \\ China \\ *E-mail: $\underline{\text { hexu@dhu.edu.cn }}$
}

doi: $10.20964 / 2019.08 .22$

Received: 20 March 2019 / Accepted: 28 April 2019 / Published: 30 June 2019

In this article, palladium nanoparticles (PdNPs) and 1, 5- diaminonaphthalene (1, 5-DAN) were electrochemically co-deposited onto multiwalled carbon nanotubes (MWCNTs) modified glassy carbon electrode (PdNPs-poly(1, 5-DAN)/MWCNTs/GCE). The morphology and properties of PdNPs-poly(1, 5-DAN)/MWCNTs/GCE were characterized by scan electron microscope (SEM), energy dispersive Xray spectrum (EDX) and electrochemical techniques. The proposed sensor exhibited an excellent electrocatalytic performance for nitrite detection. The oxidation potential for nitrite detection at the fabricated sensors was decreased $(0.792 \mathrm{~V})$ and peak current was evidently improved, mainly due to the high synergistically catalytical effect of Pd nanostructures, poly(1, 5-DAN) and MWCNTs. The results revealed that the electrooxidation mechanism of nitrite was involved two electrons transfer in the irreversible reaction at the PdNPs-poly(1, 5-DAN)/MWCNTs/GCE. The oxidation peak current of nitrite was proportional to its concentration with the linear range of $0.25 \mu \mathrm{M} \sim 0.1 \mathrm{mM}$ by amperometry, and the limit of detection (LOD) was as low as $0.08 \mu \mathrm{M}(S / N=3)$. Furthermore, as-prepared sensors had good anti-fouling property, long-term stability and excellent practical ability, which was successfully applied to detect nitrite in real water samples and gained satisfactory recoveries of $97 \% \sim 105 \%$.

Keywords: Palladium; Diaminonaphthalene; Synergistic effect; Electrooxidation

FULL TEXT 
(C) 2019 The Authors. Published by ESG (www.electrochemsci.org). This article is an open access article distributed under the terms and conditions of the Creative Commons Attribution license (http://creativecommons.org/licenses/by/4.0/). 